\title{
Expression and assembly of Norwalk virus-like particles in plants using a viral RNA silencing suppressor gene
}

\author{
Ana Cláudia Souza • Raquel Medeiros Vasques • \\ Alice Kazuko Inoue-Nagata • Cristiano Lacorte • \\ Franciele Roberta Maldaner • Eliane Ferreira Noronha • \\ Tatsuya Nagata
}

Received: 11 April 2013 / Revised: 18 June 2013 / Accepted: 18 June 2013 /Published online: 8 August 2013

(C) Springer-Verlag Berlin Heidelberg 2013

\begin{abstract}
Binary vector-based transient expression of heterologous proteins in plants is a very attractive strategy due to the short time required for proceeding from planning to expression. However, this expression system is limited by comparatively lower yields due to strong post-transcriptional gene silencing (PTGS) in the host plants. The aim of this study was to optimize a procedure for expression of norovirus virus-like particles (VLPs) in plants using a binary vector with co-expression of a PTGS suppressor to increase the yield of the target protein. The effects of four plant viral PTGS suppressors on protein expression were evaluated using green fluorescent protein (GFP) as a reporter. Constructs for both GFP and PTGS suppressor genes were co-infiltrated in Nicotiana benthamiana plants, and the accumulation of GFP was evaluated. The most effective PTGS suppressor was the $126 \mathrm{~K}$ protein of Pepper mild mottle virus. Therefore, this suppressor was selected as the norovirus capsid gene co-expression partner for subsequent studies. The construct containing the major ( $v p l)$ and minor capsid ( $v p 2)$ genes with a 3 'UTR produced a greater amount
\end{abstract}

Electronic supplementary material The online version of this article (doi:10.1007/s00253-013-5077-5) contains supplementary material, which is available to authorized users.

A. C. Souza • R. M. Vasques · F. R. Maldaner ' E. F. Noronha

T. Nagata $(\bowtie)$

Departamento de Biologia Celular, UnB,

CEP 70910-900 Brasília, DF, Brazil

e-mail: tatsuya@unb.br

A. K. Inoue-Nagata

Embrapa Vegetables, Km 09 BR 060, Rodovia Brasília-Anápolis,

Caixa Postal 218, CEP 70359-970 Brasília, DF, Brazil

C. Lacorte

Embrapa Recursos Genéticos e Biotecnologia, Parque Estação

Biológica-PqEB, Av. W5 Norte (final),

CEP 70770-917 Brasília, DF, Brazil of protein than the construct with the major capsid gene alone. Thus, the $v p 1-v p 2-3^{\prime} U T R$ and 126K PTGS suppressor constructs were co-infiltrated at middle scale and VLPs were purified by sucrose gradient centrifugation. Proteins of the expected size, specific to the norovirus capsid antibody, were observed by Western blot. VLPs were observed by transmission electron microscopy. It was concluded that protein expression in a binary vector co-expressed with the $126 \mathrm{~K}$ PTGS suppressor protein enabled superior expression and assembly of norovirus VLPs.

Keywords Binary vector · Virus like particle (VLP) . Norovirus capsid gene co-expression · Post-transcriptional gene silencing $\cdot$ PTGS suppressor gene

\section{Introduction}

Norwalk virus (NV) is the only member of the genus Norovirus in the family Caliciviridae. The NV genome is composed of single stranded positive sense RNA (approximately $7.7 \mathrm{~kb}$ in length), which generally encodes three open reading frames (ORFs). ORF1 encodes a nonstructural protein, ORF2 encodes the major capsid protein VP1, and ORF3 encodes the minor structural protein VP2 (Hardy 2005). Human NV is still uncultivable in cell culture systems, which limits studies on the mechanisms of $\mathrm{NV}$ infection and replication.

The expression of recombinant capsid proteins may result in the self-assembly of empty, non-infectious virus like particles (VLPs). VLPs of morphologically and antigenically similar to wild type virions have general application to study interaction and expression within the host (Kissmann et al. 2008; Ausar et al. 2006; Murakami et al. 2010). Several expression systems have been developed for the production of NV VLPs, including baculovirus-infected insect cell (Jiang et al. 1992), bacterial (Yoda et al. 2000), yeast (Xia et al. 
2007), transgenic plant (Zhang et al. 2006) and plant transient expression systems (Santi et al. 2008).

Initial assays of NV VLP production in plants focused on constitutive expression systems in transgenic plants; however, the system showed low VLP yields (Lai and Chen 2012). The plant virus-based transient expression systems have overcome the limitations in NV VLP yield and production speed (Santi et al. 2008; Huang et al. 2009). Nonetheless, these systems have some disadvantages as size limitations and instability of the target genes (Sainsbury et al. 2009).

As an alternative, Agrobacterium-mediated transient gene expression is a rapid and useful method for recombinant protein expression. This technique uses binary vectors harboring the gene of interest and is faster compared to the transgenic plant systems (Wydro et al. 2006; Belknap et al. 2008; Sainsbury et al. 2009). The main limitations of this technique, however, are low protein expression and high risks of triggering post-transcriptional gene-silencing (PTGS), which is part of the RNA interference mechanism for plant defense (Baulcombe 2005). This phenomenon greatly reduces and can eventually impede the expression of a recombinant protein (Wydro et al. 2006). Recently, it was demonstrated that the use of plant virus PTGS suppressors greatly reduces PTGS, increasing the expression levels of heterologous proteins by several fold in agro-infiltrated leaves (Sainsbury et al. 2009; Circelli et al. 2010).

The aim of this study was to develop a strategy to produce high amounts of NV VLPs in plants. For this purpose, four PTGS suppressor genes (HC-Pro from the potyvirus Brugmansia suaveolens mottle virus (BsMoV), 126K from the tobamovirus Pepper mild mottle virus (PMMoV), AC2 from the begomovirus Tomato severe rugose virus (ToSRV), and p19 from the tombusvirus Tomato bushy stunt virus (TBSV) were co-expressed with green fluorescent protein (GFP) reporter to test their effects on NV VLP production.

During the construction of the expression vector for the NV VLPs, a possible positive effect of $v p 2$ positioned downstream of $v p 1$ in a bicistronic construct was evaluated in the baculovirus expression system (Bertolotti-Ciarlet et al. 2003). $\mathrm{NV}$ uses the "ribosomal termination-initiation mechanism" to express the second cistron (VP2) instead of producing additional subgenomic RNA (Herbert et al. 1996). This mechanism seems to function in insect cells as well (baculovirus systems). In this study, the expression efficiency of the NV $v p 1$ construct with or without the $v p 2$ gene in plants was evaluated.

\section{Material and methods}

Amplification and cloning of RNA silencing suppressor genes and the GFP gene

Three suppressors were selected, HC-Pro from BsMoV (accession number NC 014536-Lucinda et al. 2010), 126K from PMMoV (AB550911-Oliveira et al. 2010), and AC2 from
ToSRV (NC 009607-Barbosa et al. 2009). The wellcharacterized, potent PTGS suppressor TBSV p19 protein (AJ288942) (Sainsbury et al. 2009; Lindbo 2007; Garabagi et al. 2012; Yoon et al. 2012) was used as the standard protein for comparison with the three other suppressor proteins.

Each gene was amplified by RT-PCR with the following primers: BsMoV-HC-Pro (SacII) Fwd (5'-TTA CCG CGG ACA ATG GCA ACC TCA TCA ACT TTT TGG-3') and BsMoV-HC-Pro (KpnI) Rev (5'-CGG CGG TAC CTT AAC CTA CCA AGT AAT GTT TCA TTT-3'), PMMoV-126K (SacII) Fwd (5'-TTA CCG CGG ACA ATG GCT TAC ACA CAA CAA GCT ACC-3') and PMMoV-126 K (KpnI) Rev (5'-CGC CGG TAC CCT ATT GAG TCG ACA CAT CAA CTT TG-3'), ToSRV-AC2 (SacII) Fwd (5'-TTA CCG CGG ACA ATG GCA AAT TCG TCT TCC TTA ACA CCC-3') and ToSRV-AC2 (KpnI) Rev (5'-CGG TCG GTA CCC TAG TTA AAT ATG TCG TCC CAG AAG-3'), TBSV-p19 (SacII) Fwd (5'-TTT CCG CGG ATG GAA CGA GCT ATA CAA GGA-3') and TBSV-p19 (XhoI) Rev (5'-TTT CTC GAG TTA CTC GCT TTC TTT TTC GAA GGT-3').

The amplified cDNA fragments were cloned into the pGreenII 62-SK vector (Hellens et al. 2005). After confirming the sequences of these clones, the plasmids were transferred into Agrobacterium tumefaciens GV3101-pSOUP (Hellens et al. 2005) (from the collection of EMBRAPA Genetic Resources and Biotechnology, Brasília, Brazil). Similar to the approach of Wydro et al. (2006), a modified version of GFP optimized for plant expression, mGFP4-ER (U87625) (Haseloff et al. 1997), was used as a sensitive, non-invasive reporter to assess the efficiency of PTGS suppressor accumulation. The mGFP4-ER gene was amplified using primers for SigPep-mGFP4(SacII) Fwd (5'-TCC GCG GAA CAA TGA AGA CTA ATC TTT TTC TCT TTC TCA TCT TTT CAC TTC TCC TAT CAT TAT CCT CGG CCG AAT TCA GTA AAG GAG AAG AAC TTT TCA C-3') and mGFP HDEL (KpnI) Rev (5'-TGG TAC CTT AAA GCT CAT CAT GTT TGT ATA GTT CAT CCA TGC CAT G-3') and cloned into pGreenII 62-SK to generate the plasmid pGreenII-mGFP4-ER.

Co-infiltration of PTGS suppressor candidates and mGFP4-ER genes

Agrobacterium suspensions ( $2 \mathrm{ml}$ in volume) were sedimented at $1,200 \times g$ for $10 \mathrm{~min}$. The resulting pellets were resuspended in $5 \mathrm{ml}$ of a solution containing $10 \mathrm{mM}$ MES (pH 5.5) and $150 \mu \mathrm{M}$ acetosyringone to an $\mathrm{OD}_{600}$ of 1.0. Leaves from Nicotiana benthamiana plants, approximately 6 weeks old, were infiltrated with the bacterial suspensions on their abaxial sides using a syringe without a needle. The mGFP-ER construct was co-infiltrated at a ratio of 1:1 with each of the four constructs coding the suppressors. The mGFP-ER construct and the empty pGreenII plasmid were also infiltrated as negative controls. 
Observation of fluorescence intensity and Western blot analysis

GFP fluorescence was observed by UV irradiation $(365 \mathrm{~nm}$, lamp model UVLM-28 EL, UVP) at 10 dpi (days postinfiltration) and photographed using a digital camera (CANON model EOS) with a yellow filter with a 15-s exposure. For Western blot analysis, five agro-infiltrated leaf disks from the different plants of the same treatment $(0.1 \mathrm{~g})$ were homogenized in $500 \mu \mathrm{l}$ of $1 \times \mathrm{PBS}\left(10 \mathrm{mM} \mathrm{Na}_{2} \mathrm{HPO}_{4}, 1.7 \mathrm{mM}\right.$ $\mathrm{KH}_{2} \mathrm{PO}_{4}, 140 \mathrm{mM} \mathrm{NaCl}$, and $2.7 \mathrm{mM} \mathrm{MgCl}_{2}, \mathrm{pH}$ 7.0) containing a protease inhibitor cocktail (Sigma-Aldrich, St. Louis, MO, USA).

Each homogenate $(10 \mu \mathrm{l})$ was loaded and separated by electrophoresis on $12 \%$ polyacrylamide gels. Proteins were either visualized directly by Coomassie Brilliant Blue staining or analyzed by Western blot using rabbit anti-GFP serum (Invitrogen, Carlsbad, CA, USA) and anti-rabbit IgG alkaline phosphatase conjugate with colorimetric development in nitro blue tetrazolium and 5-bromo-4-cloro-3-indolil phosphate solution. Signals were measured using an Image Scanner III (LabScan 6.0, GE Healthcare) and Image Master 2D Platinum 7 software (GE Healthcare).

Amplification and cloning of three different constructs from the NV isolate

For production of NV VLPs, three constructs were tested. The first construct contained only the $v p 1$ ORF (accession number KC715794). The second construct was codon-optimized $v p 1$ gene to $N$. benthamiana codon usage (vpl-CodOpt, synthesized at Epoch Life Science, TX, USA) (KC907392). The third construct contained the $v p 1, v p 2$, and the 3'UTR containing a poly $\left(\mathrm{A}_{50}\right)$ tail of an isolate from NV genogroup II genotype 4 (GII.4) subtype 2004 (isolated in 2006 at Brasilia, Brazil) (KC715794). To obtain the genomic fragment, reverse transcription (RT)-PCR was performed using the oligodT ${ }_{50} \mathrm{M} 4$ PacI primer (5'-TCA GCA CTG ACC CTT TTG AAT TAA $\left.\mathrm{T}_{50}-3^{\prime}\right)$ for the RT reaction, followed by PCR using the anchor primer M4 (5'-TCA GCA CTG ACC CTT TTG-3') and the Noro II 3' For primer (5'-GGA AAA ACG ACT GCT GGA ACG G-3'). PCR was performed using LongAmp DNA polymerase (New England Biolabs, Ipswich, MA, USA). Amplicons were cloned into the pGEM-T Easy vector (Promega, Madison, WI, USA). Three clones were selected and sequenced for confirmation. A second PCR was performed using a selected cDNA clone with the following primer pairs: NoroGII4-7 NotI for (5'-AAA GCG CCG CAA CAA TGA AGA TGG CGT CGA ATG AC-3') and NoroGII4-7 SacI Rev (5'-AAG AGC TCT TAT AAT GCA CGT CTG CGC C-3') for $v p 1$ construct or NoroGII4-7 NotI For and PacI-M4-SacI (5'-TTT GAG CTC TTT TCC CAG TCA CGA CTT AAT TAA-3') for $v p 1-v p 2-3^{\prime}$
UTR construct. These two amplicons, $v p 1$ and $v p 1-v p 2-3$ 'UTR and one synthesized construct vp1-CodOpt were then cloned into the pRAPs vector at the NotI and SacI sites. The pRAP plasmid contains dual Cauliflower mosaic virus 35S promoters upstream of the leader sequence from the Alfalfa mosaic virus 5'UTR and downstream a nopaline synthase terminator. The cassette was digested with $A s c \mathrm{I}$ and PacI and subcloned into the binary vector pBINPLUS (Engelen et al. 1995). A. tumefaciens GV3101 strain (from the collection of EMBRAPA Genetic Resources and Biotechnology, Brasília, Brazil) was transformed with the final binary vector after confirmation of subcloning by restriction enzyme profiling of the selected plasmids.

Expression of NV coat proteins in plants and partial purification of NV VLPs

Overnight, Agrobacterium suspensions $\left(28{ }^{\circ} \mathrm{C}\right.$ at $180 \mathrm{rpm}$ ) containing NV vp1, vp1-CodOpt, vp1-vp2-3' UTR, and $126 \mathrm{~K}$ PTGS suppressor gene constructs were centrifuged separately at $1,200 \times g$ for $10 \mathrm{~min}$. Each pellet was resuspended in a solution containing $10 \mathrm{mM}$ MES ( $\mathrm{pH} 5.5$ ) and $50 \mu \mathrm{M}$ acetosyringone and then incubated at $28{ }^{\circ} \mathrm{C}$ overnight for transgene induction. These suspensions were centrifuged again $(1,200 \times g$ for $10 \mathrm{~min}$ ), and the resulting pellets were resuspended with Murashige-Skoog medium (Sigma-Aldrich) containing $150 \mu \mathrm{M}$ acetosyringone to an $\mathrm{OD}_{600}$ of 2.0. Each NV construct ( $v p 1, v p 1-C o d O p t$, or $v p 1-v p 2-3$ 'UTR) was mixed with the Agrobacterium suspension containing the $126 \mathrm{~K}$ PTGS suppressor $\left(\mathrm{OD}_{600}=2.0\right)$ at a $1: 1$ proportion. $N$. benthamiana leaves, 6 to 7 weeks old, were infiltrated with this mixed suspension as described previously. Coat protein accumulation was evaluated at 3 dpi by Western blot using a polyclonal antibody against NV GII.4 (kindly provided by Dr. Shinich Kobayashi, Aichi Prefectural Institute of Public Health, Nagoya, Japan).

After choosing $v p 1-v p 2-3^{\prime} U T R$ as the optimal construct, $40 N$. benthamiana plants were infiltrated as described previously for VLP purification. Leaves were harvested at 3 dpi and NV VLPs were partially purified according to Santi et al. (2008) with modifications. VLPs were purified using a continuous 10-40\% sucrose gradient prepared in phosphate buffer ( $\mathrm{pH}$ 5.3) with centrifugation at $217,485 \times \mathrm{g}$ using a Beckman SW40 rotor (Beckman Coulter, Fullerton, CA, USA) for $2 \mathrm{~h}$ at $4{ }^{\circ} \mathrm{C}$. The purified NV VLPs were analyzed by SDS-PAGE and Western blot as previously described. The assembly of VLPs was evaluated by observation of semi-purified VLP preparations using a 200 mesh grid and a JEM 1011 electron microscope (JEOL, Tokyo, Japan) according to Maramorosch and Koprowski (1984). 


\section{Results}

mGFP-ER accumulation in plants co-infiltrated with suppressor gene constructs

The mGFP4-ER construct was used as a reporter gene to evaluate the enhancement effects of PTGS suppressor genes on heterologous protein accumulation. Half of each leaf was infiltrated with the mGFP-ER construct and the empty pGreen II 64-SK (control). The other half of each leaf was infiltrated with both constructs (mGFP-ER and the suppressor). After 5 dpi, a higher intensity of GFP fluorescence was observed for all tested constructs (HC-Pro of BsMoV, 126K of PMMoV, AC2 of ToSRV, and p19 of TBSV) compared to the control (mGFP-ER + empty pGreenII) (Fig. 1). This experiment was repeated three times to confirm the results. It was remarkable that the infiltration of $126 \mathrm{~K}$ from PMMoV in one half of the $N$. benthamiana leaf influenced mGFP-ER expression on the other half of the leaf (Fig. 1). In all cases, the expression of mGFP-ER after infiltration with mGFP-ER + empty pGreenII was higher when PMMoV $126 \mathrm{~K}$ was infiltrated on the other side. By visual evaluation, the expression of PMMoV $126 \mathrm{~K}$ resulted in the strongest mGFP-ER expression, followed by BsMoV HC-Pro, TBSV p19, and ToSRV AC2. To select the best suppressor for the expression of an NV protein, the mGFP-ER accumulation level was analyzed by Western blot at 6 dpi (Fig. 2 and Fig. S1). The level of mGFP-ER accumulation detected by Western blot was recorded using an Image Scanner III (LabScan 6.0, GE Healthcare) to confirm that the highest intensity occurred for $126 \mathrm{~K}$ from PMMoV, followed by HC-Pro from BsMoV, p19 from TBSV, and AC2 from ToSRV. The highest level of mGFP-ER accumulation occurred with co-expression of 126K from PMMoV (Fig. 2), followed by BsMoV HCPro and AC2 from ToSRV. Therefore, the 126K PTGS suppressor gene from $\mathrm{PMMoV}$ was chosen for expression of the NV VLPs.

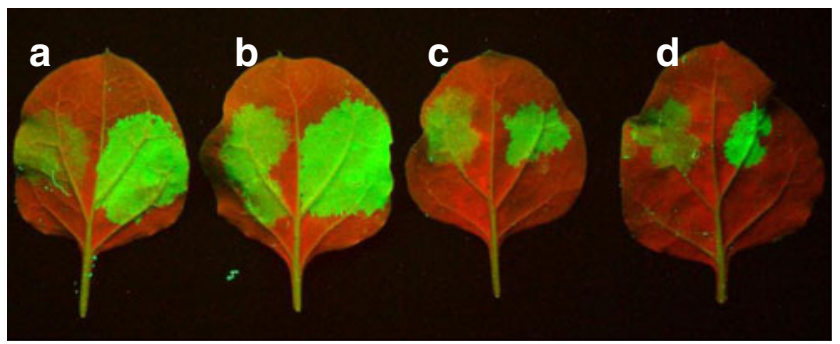

Fig. 1 Comparison of mGFP-ER signal intensity by co-infiltrations of PTGS suppressors. Fluorescence was observed by UV radiation on infiltrated $N$. benthamiana leaves, $5 \mathrm{dpi}$. The left side of each leaf was infiltrated with only mGFP. The right side of each leaf was infiltrated with mGFP-ER and the suppressors a HC-Pro BsMoV, b $126 \mathrm{~K}$ PMMoV, c AC2 ToSRV, and d p19 TBSV

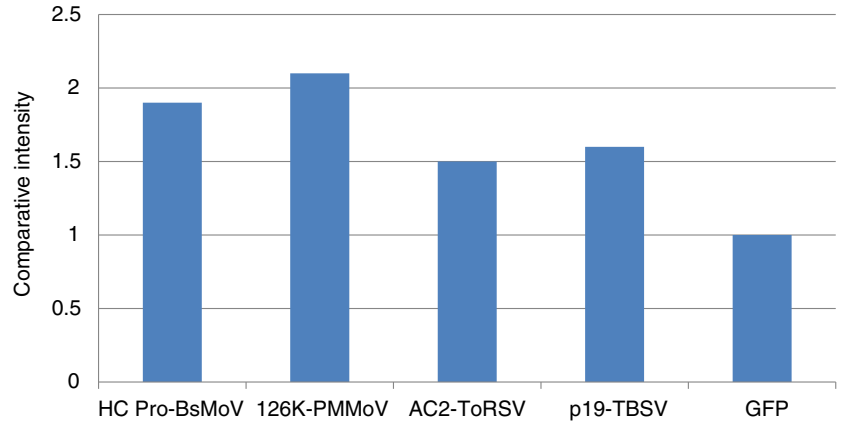

Fig. 2 Volume and intensity proportion from Western blot signals obtained for each construct. Vertical line assigned values relative to 1 for mGFP without silencing suppressor. Horizontal line, mGFP-ER + HC-Pro BsMoV, mGFP-ER + 126K PMMoV, mGFP-ER + AC2 ToSRV, mGFP-ER + p19 TBSV, and mGFP-ER without suppressor (empty pGreenII)

The $v p 1-v p 2-3^{\prime} U T R$ construct increased the expression of NV-CP

It is known that NV VLPs can be obtained by expression of only the major capsid protein (VP1). However, in a baculovirus expression system, the simultaneous expression of VP1 and VP2 (minor capsid gene) further increased VLP accumulation (Bertolotti-Ciarlet et al. 2003). Because higher VP1 expression levels are desired, we tested three strategies, expression of VP1, expression of vp1-CodOpt (Codon optimized to $N$. benthamiana plant expression), and simultaneous expression of VP1 and VP2 from an isolate of the NV GII.4 subtype 2004 (isolated in 2006 at Brasilia, Brazil). In the latter strategy, the $v p 2$ (ORF3) gene and 3 'UTR including a poly $\left(\mathrm{A}_{50}\right)$ tail were added to further contribute to the expression efficiency. These constructs were agro-infiltrated into $N$. benthamiana leaves. After $3 \mathrm{dpi}$, six leaf disks (total of $0.3 \mathrm{~g}$ ) from each treatment were macerated together with $1 \times$ PBS $(600 \mu \mathrm{l})$ and only a part of the solution $(10 \mu \mathrm{l}$, corresponding to $6 \mathrm{mg}$ of fresh tissue) was analyzed by Western blot using an anti-VP1 antibody. This experiment was repeated three times, and in all cases, the highest protein accumulation was observed for the $v p 1-v p 2-3$ 'UTR construct (Fig. 3), and the production efficiency of VP1 was estimated at approximately $1 \mathrm{mg}$ per $1 \mathrm{~g}$ of fresh leaf by Western blot image analysis. Inoculation with the $v p 1$ construct alone or $v p 1-C o d O p t$ resulted in lower VP1 accumulation. Therefore, the $v p 1-v p 2-3 ' U T R$ construct was chosen for expression of NV VLPs in a coexpression system with the $126 \mathrm{~K}$ PTGS suppressor gene.

The NV VP1 protein expressed in plants showed only single band by Western blot, although the positive NV VP1 control made by insect cells showed the double bands. This difference was also observed in previous reports (in "Discussion" section). 


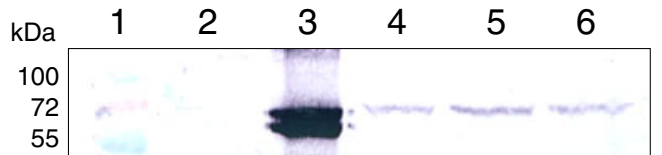

Fig. 3 Western blot analysis of extracts from $N$. benthamiana leaves inoculated with VP1 expression constructs at 3 dpi using an anti-VP1 antibody. 1 Protein marker (Fermentas pre-stained), 2 negative control ( $N$. benthamiana leaf with mock inoculation), 3 positive control (VLPs made in insect cells, $7 \mu \mathrm{g}), 4 v p 1+126 \mathrm{~K} \mathrm{PMMoV}, 5 v p 1-v p 2-3^{\prime} U T R+$ $126 \mathrm{~K} \mathrm{PMMoV}$, and 6 vpl-CodOtp $+126 \mathrm{~K} \mathrm{PMMoV}$

NV VLP assembly in tissue infiltrated with $v p 1-v p 2-3^{\prime} U T R$ and the $126 \mathrm{~K}$ suppressor

A total of $40 \mathrm{~N}$. benthamiana plants (two to three upper leaves for each plant) were infiltrated with the constructs containing NV $v p 1-v p 2-3^{\prime} U T R$ and the 126K PMMoV suppressor gene. VLPs were semi-purified from these tissues and observed with an electron microscope. Centrifuged gradients were collected in ten fractions. The CP-rich fraction was confirmed by Western blot (Fig. 4a). Particles of approximately $40 \mathrm{~nm}$ in diameter were clearly detected in this fraction by transmission electron microscopy (Fig. 4b). It was concluded that the co-inoculation of the constructs containing $v p 1-v p 2-3^{\prime} U T R$ and the $126 \mathrm{~K}$ PMMoV enabled production of NV VLPs.

\section{Discussion}

Several reports of NV VLP production using plant protein expression systems have been available (Kralovetz et al. 2010; Lai and Chen 2012; Santi et al. 2006, 2008; Tiwari

a
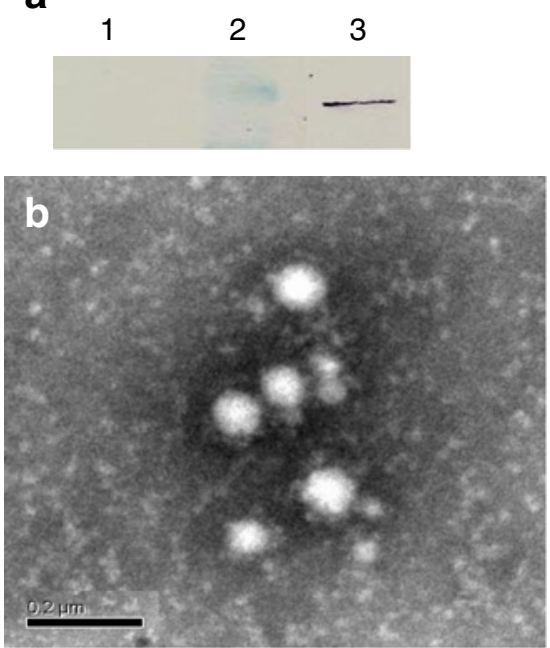

Fig. 4 The analysis of semi-purified VLPs from plant extracts. a Western blot analysis of the gradients from the VLP suspensions. 1 Negative control, 2 protein marker (SIGMA-ALDRICH, pre-stained; Blue band showed $90 \mathrm{kDa}$ ), and $3 v p 1-v p 2-3^{\prime} U T R+126 \mathrm{~K}$ PMMoV. b Electron micrograph of the VLP suspension. Bar $=0.2 \mu \mathrm{m}$ et al. 2009; Daniell et al. 2009; Zhang et al. 2006; Huang et al. 2009). These reports provide protocols for production of viable VLPs at low costs and in large quantities. More recently, modified transient expression systems using viral vectors (known as magnICON) have offered high efficiency, rapid VLP production (Santi et al. 2008; Lai and Chen 2012; Huang et al. 2009). However, magnICON systems could be limited by the size of the gene insert that can be accommodated. Trials for NV VLP expression are all based upon constructs that only encode $v p 1$. Therefore, longer inserts (for example the vp1-vp2-3'UTR cassette, ca. 2.6 Kbp) have not been attempted in plant expression system. It is expected that co-expression of VP1 and VP2 enhances the stability of VLPs (Bertolotti-Ciarlet et al. 2003), an essential property for vaccine development. Therefore, our group used binary vector systems for VLP production.

The $\mathrm{pEAQ}$ vectors are known for their small plasmid size (ca. $7 \mathrm{Kbps}$ ). These vectors were constructed by removing more than $7 \mathrm{Kbp}$ of the non-essential region from the pBINPLUS backbone and T-DNA region and by adding the TBSV p19 PTGS suppressor gene (Sainsbury et al. 2009). The vector provided an easy and quick tool for production of viral antigens. We postulated that other PTGS suppressors may increase expression efficiency because some viruses that infect $N$. benthamiana induce more severe symptoms in this plant than others. Thus, we sought to utilize putative PTGS suppressor gene from these viruses. The choice of the $126 \mathrm{~K}$ protein from PMMoV as the PTGS suppressor partner for production of NV VLPs was made due to its superior enhancement effect on expression of mGFP-ER compared to the other tested suppressors (HC-Pro BSMoV, AC2 from ToSRV, and p19 TBSV). Lower target protein accumulation occurred for $\mathrm{AC} 2$ from the begomovirus Tomato golden mosaic virus compared to HC-Pro from Tobacco etch virus and p19 from Cymbidium ringspot virus according to Wang et al. (2005). Our trial corroborated these results. According to Hamilton et al. (2002), Mallory et al. (2001), and Wydro et al. (2006), several factors influence the genetic requirements for gene silencing and the suppressor response including the nature of the target protein, the time point that the sample is analyzed (dpi), the types of binary vectors used and the lines of $N$. benthamiana and A. tumefaciens. Therefore, tests performed with PTGS suppressors must be standardized for selection of a good binary vector.

For NV VLP expression, the vp1-vp2-3'UTR construct was chosen because it produced a higher protein yield compared to the $v p 1$ only construct. This finding is supported by the observations of Bertolotti-Ciarlet et al. (2003) in insect cells, implying that the "ribosomal termination-initiation mechanism" is also functional in plant cells. For a stable NV VLP production, the simultaneous expression of VP2 with VP1 seems very important. Therefore, our binary vector system may represent a valuable alternative to baculovirus expression systems. 
In this study, the plant-expressed NV VP1 always showed as single band in Western blot analysis. However, VP1 prepared by baculovirus system showed often double bands $(58 \mathrm{kDa}$ and $56 \mathrm{kDa}$ ) by Western blot in previous reports (Huhti et al. 2010; Blazevic et al. 2011; Koho et al. 2012) and also in our study when used as a positive control (Fig. 3). The smaller $56 \mathrm{kDa}$ band represents a product that is truncated by 34 amino acids from its N-terminal end possibly by host protease as protease $\mathrm{K}$ or thermolysin (Koho et al. 2012). However, NV VP1 expressed in plants showed only a single band by Western blot as reported previously (Santi et al. 2008; Lai and Chen 2012) and also in our study (Fig. 3). It is indicative that the plant cells do not contain such proteases which cleave NV VP1.

It was remarkable that the $\mathrm{NV}$ expression using the $v p 1$ CodOpt construct produced a similar protein accumulation level as the $v p 1$ construct, which was isolated from viral cDNA by RT-PCR (Fig. 3). In this study, the attempt to use the codon optimization did not produce the expected result. Such observations were already reported by Maclean et al. (2007) who observed that the native L1 protein of HPV accumulated in higher amounts than the plant codonoptimized gene using binary expression vectors in $N$. benthamiana plants. It was concluded that the codon optimization cannot always be considered the best strategy to increase the protein expression efficiency.

In our study, four different PTGS suppressor genes were preliminary evaluated and the best one was chosen to produce an efficient expression tool. The target protein expression using a binary vector co-expressed with this PTGS suppressor (126K from PMMoV) enabled higher accumulation and assembly of norovirus VLPs. However, additional studies will be required to improve the target protein accumulation level, such as those related to their subcellular localization and reduction of plant cell proteolysis.

Acknowledgments The work was funded by Fundação de Apoio à Pesquisa do Distrito Federal (FAPDF, Brazil) for a research grant and by "Conselho Nacional de Desenvolvimento Científico e Tecnológico" (CNPq, Brazil) for the DSC scholarship to the first author. The third, sixth, and seventh authors are research fellows of $\mathrm{CNPq}$

\section{References}

Ausar SF, Foubert TR, Hudson MH, Vedvick TS, Middaugh CS (2006) Conformational stability and disassembly of Norwalk virus-like particles effect of $\mathrm{pH}$ and temperature. J Biol Chem 281:1947819488. doi:10.1074/jbc.M603313200

Barbosa JC, Barreto SS, Inoue-Nagata AK, Reis MS, Firmino AC, Bergamin Filho A, Rezende JAM (2009) Natural infection of Nicandra physaloides by Tomato severe rugose virus in Brazil. J Gen Plant Pathol 75:440-443. doi:10.1007/s10327-009-0198-5

Baulcombe D (2005) RNA silencing. Trends Biochem Sci 30:290-293. doi:10.1016/j.tibs.2005.04.012
Belknap WR, Rockhold DR, McCue KF (2008) pBINPLUS/ARS: an improved plant transformation vector based on pBINPLUS. Biotech 44:753-756. doi:10.2144/000112731

Bertolotti-Ciarlet A, Crawford SE, Hutson AM, Estes MK (2003) The $3^{\prime}$ end of Norwalk virus mRNA contains determinants that regulate the expression and stability of the viral capsid protein VP1: a novel function for the VP2 protein. J Virol 77:11603-11615. doi:10. 1128/JVI.77.21.11603-11615.2003

Blazevic V, Lappalainen S, Nurminen K, Huhti L, Vesikari T (2011) Norovirus VLPs and rotavirus VP6 protein as combined vaccine for childhood gastroenteritis. Vaccine 29:8126-8133. doi:10. 1016/j.vaccine.2011.08.026

Circelli P, Domini M, Villani ME, Benvenuto E, Marusic C (2010) Efficient Agrobacterium-based transient expression system for the production of biopharmaceuticals in plants. Bioeng Bugs 1:221224. doi:10.4161/bbug.1.3.11722

Daniell H, Singh ND, Mason H, Streatfield SJ (2009) Plant made vaccine antigens and biopharmaceuticals. Trends Plant Sci 14:669-679. doi:10.1016/j.tplants.2009.09.009

Engelen V, Molthoff FA, Conner AJ, Nap JP, Pereira A, Stiekema WJ (1995) pBINPLUS - an improved plant transformation vector based on pBIN19. Transgenic Res 4:288-290. doi:10.1007/ BF01969123

Garabagi F, Gilbert E, Loos A, McLean MD, Hall JC (2012) Utility of the P19 suppressor of gene-silencing protein for production of therapeutic antibodies in Nicotiana expression hosts. Plant Biotechnol J 10:1118-1128. doi:10.1111/j.1467-7652.2012.00742.x

Hamilton A, Voinnet O, Chappell L, Baulcombe D (2002) Two classes of short interfering RNA in RNA silencing. EMBO J 21:46714679. doi:10.1093/emboj/cdf464

Hardy ME (2005) Norovirus protein structure and function. FEMS Microbiol Lett 253:1-8. doi:10.1016/j.femsle.2005.08.031

Haseloff J, Siemering KR, Prasher DC, Hodge S (1997) Removal of a cryptic intron and subcellular localization of green fluorescent protein are required to mark transgenic Arabidopsis plants brightly. Proc Natl Acad Sci 94:2122-2127

Hellens RP, Allan AC, Friel EN, Bolitho K, Grafton K, Templeton MD, Karunairetnam S, Gleave AP, Laing WA (2005) Transient expression vector for functional genomics, quantification of promoter activity and RNA silencing in plants. Plant Methods 1:13. doi:10. 1186/1746-4811-1-13

Herbert TP, Brierley I, Brown TD (1996) Detection of the ORF3 polypeptide of feline calicivirus in infected cells and evidence for its expression from a single, functionally bicistronic, subgenomic mRNA. J Gen Virol 77:123-127. doi:10.1099/0022-1317-77-1-123

Huang Z, Chen Q, Hjelm B, Arntzen C, Hugh M (2009) A DNA replicon system for rapid high-level production of virus like particles in plants. Biotechnol Bioeng 103:706-714. doi:10.1002/bit. 22299

Huhti L, Blazevic V, Nurminem K, Koho T, Hytonen VP, Vesikari T (2010) A comparison of methods for purification and concentration of noroviru GII-4 capsid virus-like particles. Arch Virol 155:1855-1858. doi:10.1007/s00705-010-0768-Z

Jiang XI, Wang MIN, Graham DY, Estes MK (1992) Expression, selfassembly, and antigenicity of the Norwalk virus capsid protein. J Virol 66:6527-6532

Kissmann J, Ausar SF, Roubert TR, Brock J, Switzer MH, Detzi EJ, Vedyick TS, Middaugh R (2008) Physical stabilization of Norwalk virus-like particles. J Pharm Sci 97:4208-4212. doi:10.1002/jps. 21315

Koho T, Mantyla T, Laurinmaki P, Huhti L, Butcher SJ, Vesikari T, Kulomaa MS, Hytonen VP (2012) Purification of norovirus-like particles (VLPs) by ion exchange chromatography. J Virol Methods 181:6-11. doi:10.1016/j.jviromet.2012.01.003

Kralovetz MH, Mason HS, Chen Q (2010) Norwalk virus-like particles as vaccines. Expert Rev Vaccines 9:299-307. doi:10.1586/erv.09.163 
Lai H, Chen Q (2012) Bioprocessing of plant-derived virus-like particles of Norwalk virus capsid protein under current good manufacture practice regulations. Plant Cell Rep 31:573-584. doi:10.1007/ s00299-011-1196-6

Lindbo JA (2007) High-efficiency protein expression in plants from agroinfection-compatible Tobacco mosaic virus expression vectors. Plant Physiol 145:1232-1240. doi:10.1104/pp.107.106377

Lucinda N, Inoue-Nagata AK, Kitajima EW, Nagata T (2010) Complete genome sequence of Brugmansia suaveolens mottle virus, a potyvirus from an ornamental shrub. Arch Virol 155:1729-1732. doi:10.1007/s00705-010-0798-6

Maclean J, Koekemoer M, Olivier AJ, Stewart D, Hitzeroth II, Rademacher T, Fischer R, Williamson AL, Rybicki EP (2007) Optimization of human papillomavirus type 16 (HPV-16) L1 expression in plants: comparison of the suitability of different HPV$16 \mathrm{~L} 1$ gene variants and different cell-compartment localization. J Gen Virol 88:1460-1469. doi:10.1099/vir.0.82718-0

Mallory AC, Ely L, Smith TH, Marathe R, Anandalakshmi R, Fagard M, Vaucheret H, Pruss G, Bowman L, Vance VB (2001) HC-Pro suppression of transgene silencing eliminates the small RNAs but not transgene methylation or the mobile signal. Plant Cell 13:571583. doi:10.1105/tpc.13.3.571

Maramorosch K, Koprowski H (1984) Immunosorbent electron microscopy in plant virus studies. In: Maramorosch K, Koprowski H (eds) Methods in Virology, vol III. Academic, New York, pp 85-101

Murakami K, Suzuki S, Aoki N, Nadano D, Uchida K, Yamashita K, Oka T, Katayama K, Takeda N, Matsuda T (2010) Binding of Norovirus virus-like particles (VLPs) to human intestinal Caco-2 cells and the suppressive effect of pasteurized bovine colostrum on this VLP binding. Biosci Biotechnol Biochem 74:541-547. doi:10.1271/bbb. 90729

Oliveira LM, Inoue-Nagata AK, Nagata T (2010) Complete genome nucleotide sequence of Pepper mild mottle virus isolated in the Federal District, Brazil. Trop Plant Pathol 35:373-376

Sainsbury F, Thueemann EC, Lomonossoff GP (2009) pEAQ: versatile expression vectors for easy and quick transient expression of heterologous proteins in plants. Plant Biotechnol J 7:682-693. doi:10.1111/j.1467-7652.2009.00434.x

Santi L, Huang Z, Mason H (2006) Virus like particles production in green plants. Methods 40:66-76. doi:10.1016/j.ymeth.2006.05.020

Santi L, Batchelor L, Huang Z, Hjelm B, Kilbourne J, Arntzen CJ, Chen Q, Mason HS (2008) An efficient plant viral expression system generating orally immunogenic Norwalk virus-like particles. Vaccine 26:1846-1854. doi:10.1016/j.vaccine.2008.01.053

Tiwari S, Verma PC, Singh PK, Tuli R (2009) Plants as bioreactors for the production of vaccine antigens. Biotechnol Adv 27:449-467. doi:10.1016/j.biotechadv.2009.03.006

Wang H, Buckley KJ, Yang X, Buchamann RC, Bisaro DM (2005) Adenosine kinase inhibition and suppression of RNA silencing by geminivirus AL2 and L2 proteins. J Virol 79:7410-7418. doi:10. 1128/JVI.79.12.7410-7418.2005

Wydro M, Kozubek E, Lehmann P (2006) Optimization of transient Agrobacterium-mediated gene expression system in leaves of Nicotiana benthamiana. Acta Biochim Pol 53:289-298

Xia M, Farkas T, Jiang XI (2007) Norovirus capsid protein expressed in yeast forms virus-like particles and stimulates systemic and mucosal immunity in mice following an oral administration of raw yeast extracts. J Med Virol 79:74-83. doi:10.1002/jmv.20762

Yoda T, Terano Y, Shimada A, Suzuki Y, Yamazaki K, Sakon N, Oishi I, Utagawa ET, Okuno Y, Shibata T (2000) Expression of recombinant Norwalk-like virus capsid proteins using a bacterial system and the development of its immunologic detection. J Med Virol 60:475-481. doi:10.1002/(SICI)1096-9071(200004)60:4<475::AID-JMV17>3.0. $\mathrm{CO} ; 2-\mathrm{B}$

Yoon JY, Han KS, Park HY, Choi SK (2012) Comparative analysis of RNA silencing suppression activities between viral suppressors and an endogenous plant RNA-dependent RNA polymerase. Virus Genes 44:495-504. doi:10.1007/s11262-012-0725-X

Zhang X, Buehner NA, Hutson AM, Estes MK, Mason HS (2006) Tomato is a highly effective vehicle for expression and oral immunization with Norwalk virus capsid protein. Plant Biotechnol J 4:419-432. doi:10.1111/j.1467-7652.2006.00191.x 